\title{
Locoregional Therapy, Immunotherapy and the Combination in Hepatocellular Carcinoma: Future Directions
}

\author{
Meaghan S. Dendy a Johannes M. Ludwig ${ }^{a, b}$ Stacey M. Stein ${ }^{c, d}$ \\ Hyun S. Kim ${ }^{\text {a, c, d }}$ \\ aDivision of Interventional Radiology, Department of Radiology and Biomedical \\ Imaging, Yale School of Medicine, New Haven, CT, USA; ${ }^{b}$ Department of Diagnostic and \\ Interventional Radiology and Neuroradiology, University Hospital Essen, University of \\ Duisburg-Essen, Essen, Germany; ${ }^{c}$ Division of Medical Oncology, Department of Internal

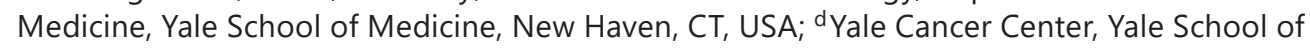 \\ Medicine, New Haven, CT, USA
}

\section{Keywords}

Locoregional therapy $\cdot \mathrm{HCC} \cdot$ Immunotherapy $\cdot$ Hepatocellular carcinoma

\begin{abstract}
Image-guided locoregional therapies (LRTs) have long been a vital part of treatment regimens for hepatocellular carcinoma (HCC). Ablation, chemoembolization, and radioembolization are examples of commonly used treatment techniques for HCC. This review describes the various methods utilized to treat HCC in the field of interventional oncology and also focuses on new and novel treatment concepts being developed in the field including the use of novel immunotherapy agents and combination therapy of LRTs with immunotherapy.
\end{abstract}

(c) 2019 S. Karger AG, Basel

\section{Introduction}

Hepatocellular carcinoma (HCC) is the fifth most common cancer worldwide and is currently the third most common cause of cancer-related mortality [1, 2]. Multidisciplinary tumor management is the standard of care and depends on tumor stage, patient performance status, and liver function at the time of diagnosis and treatment. Standard of care is early resection for those patients who are eligible for surgery and fall within the Barcelona Cancer of the Liver Clinic (BCLC) staging system [3, 4]. Meeting Milan criteria is generally required before patients are deemed suitable for orthotopic liver transplant [5]. 

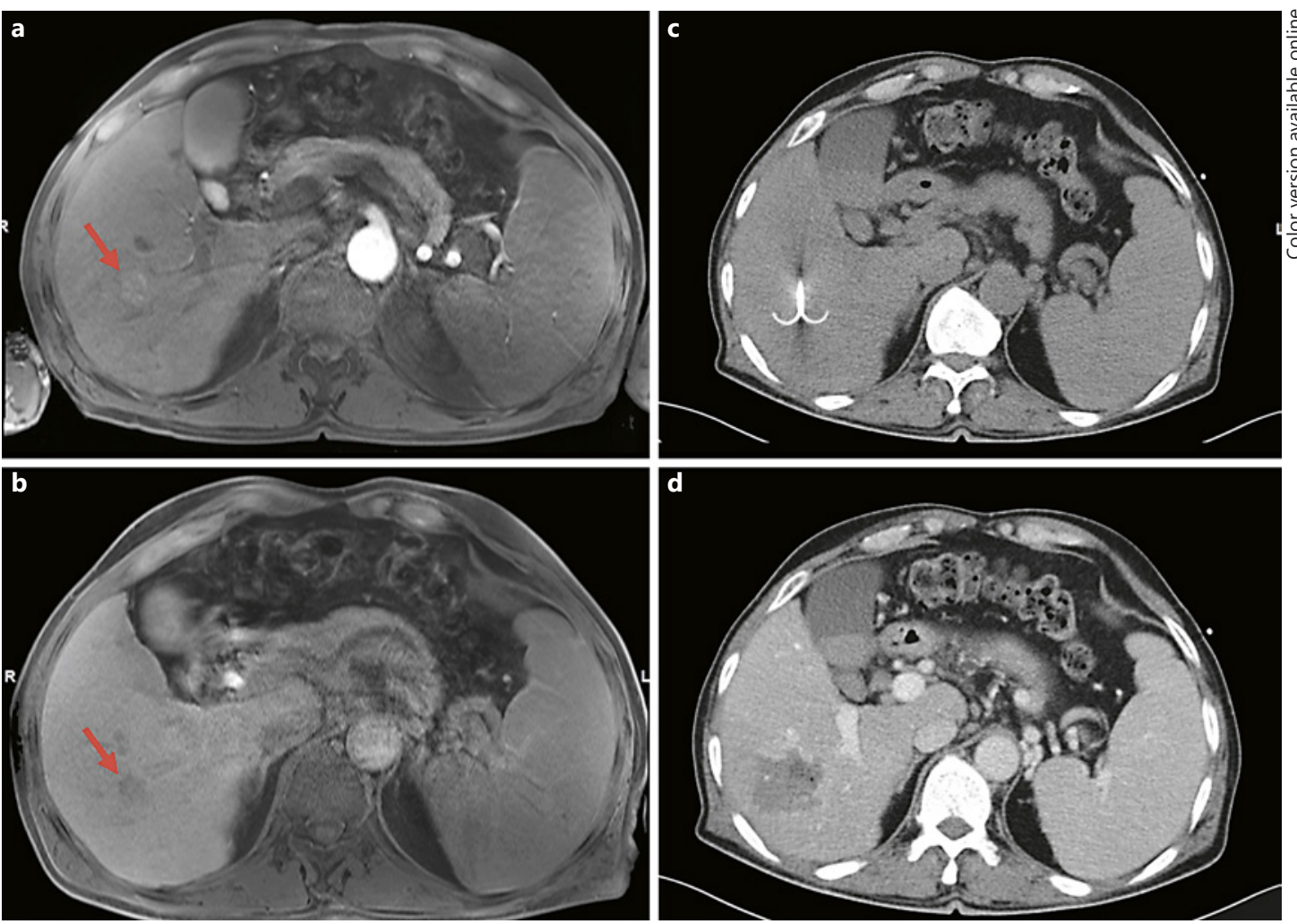

Fig. 1. RFA in HCC. A 60-year-old patient with chronic hepatitis B and D and a biopsy-proven HCC lesion in the right liver lobe. T1-weighted MRI gradient echo imaging with intravenous contrast agent shows increased arterial enhancement (a) and venous washout MRI (b). HCC lesion was treated by radiofrequency ablation. Probe placement (c) with posttreatment ablation cavity (d) on contrast-enhanced CT imaging. No recurrence was observed within the last 9 months of follow-up.

Image-guided locoregional therapies (LRTs) are available for those patients in whom resection or transplant is not a viable option. For early- and intermediate-stage HCC (Stage A and B), LRTs are available and include ablation and transarterial chemoembolization (TACE). Radioembolization is usually reserved for intermediate- to advanced-stage HCC cases and those cases that have invasion of the portal vasculature [6].

\section{Ablation}

There are multiple ablation modalities that can be useful in the treatment of HCC lesions falling outside criteria for surgical treatment. Radiofrequency ablation (RFA) remains the most commonly used option in those patients with BCLC $O$ and A stage disease, as can be seen by an example shown in Figure $1[7,8]$. RFA probes supply low-voltage alternating current to the lesion in order to heat and kill the tumor cells [9-11]. Obvious benefits of RFA compared to surgery are its minimally invasive nature, lower rate of complications, and decreased cost of treatment [12]. Data are conflicting regarding the outcomes of RFA versus surgery. Liu et al. [9] showed that survival rates at 1,2 , and 5 years were equivocal despite showing that local recurrence was more common with RFA. Zhou et al. [10] demonstrated that surgery provides better survival rates in those patients receiving surgery for lesions greater than $3 \mathrm{~cm}$, while 


\section{Liver Cancer}

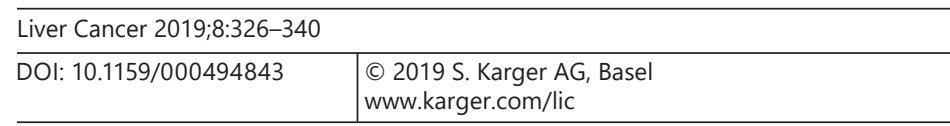

Dendy et al.: Locoregional Therapy, Immunotherapy and the Combination in HCC

those tumors less than $3 \mathrm{~cm}$ showed equal survival rates between RFA and surgically resected lesions.

Chemical ablation with percutaneous absolute ethanol injection is also still utilized, mainly in those lesions where RFA is not feasible due to proximity of vital structures [13]. The ethanol causes coagulative necrosis via dehydrated fixation and results in death of tumor cells. Optimum results have been observed when lesions are less than $2 \mathrm{~cm}$ in diameter $[14,15]$.

Another common form of ablation is cryoablation. Temperatures of -20 to $-60^{\circ} \mathrm{C}$ are applied to target tumor tissue with resulting tissue damage. An advantage of cryoablation is the decreased rates of gallbladder or bowel injury and less painful stimuli in those lesions located close to the diaphragm [16-18]. Studies have now shown that despite cryoablation not allowing for postablation tract cautery, there is a comparable risk of bleeding when hemostatic agents are used [19]. The rates of survival seen after cryoablation are also similar to RFA, with one study estimating 81.4 and $60.3 \%$ survival at 1 and 3 years, respectively [20].

Microwave ablation can also be used in treating HCC by increasing the thermal temperature of surrounding tissues, causing coagulative necrosis and resulting cell death [21, 22]. The efficiency of microwave ablation allows for increased volume of necrosis, better vessel coagulation, and decreased ablation times [22]. Introduction of second-generation microwave ablation technology over the past 5 years has yielded better consistency across ablations, larger ablation zones, and increased sphericity. This is made possible by the addition of an internal cooling agent, usually water or gas, within the probes [23]. In comparing the effectiveness of microwave ablation and surgical resection, one study showed that the survival rates at 1-, 3-, and 5-year follow up was 91.2, 72, and 59.8\%, respectively. Here, the 5-year survival rate was shown to correspond with survival seen with surgical resection [24, 25]. Multiple studies focusing on lesions less than $3 \mathrm{~cm}$ in size showed no significant difference in survival or effectiveness between microwave ablation and surgical resection [26, 27]. In the comparison of microwave ablation and RFA, Zhang et al. [28] looked at the effectiveness of treatment in lesions up to $5 \mathrm{~cm}$ in size. A complete response was seen in $86.7 \%$ of microwave ablation lesions, as compared to the $83.4 \%$ response seen in RFA-treated lesions. However, another study by Potretzke et al. [29] showed significant superiority of microwave ablation when compared to RFA in that microwave ablation yielded lower local tumor progression.

Irreversible electroporation (IRE) is the most recent trend in ablation treatments of HCC lesions. The mechanism of cell death includes the creation of nanopores in tumor cell membranes by high-voltage electric currents [30]. As a nonthermal ablative option, IRE can be utilized in those lesions located centrally in the liver and also in those lesions located near vital structures [31,32]. Varying response rates have been reported following IRE, with 73 and $82.3 \%$ complete response rates being recorded in 2 small cohort trials [33, 34]. However, Cheung et al. [33] recorded a 93\% complete response after IRE when specifically treating tumors less than $3 \mathrm{~cm}$ in size.

High-intensity focused ultrasound (HIFU) involves multiple transducers focusing ultrasound beams on an individual lesion with resulting tumor tissue being destroyed by vibrational heat energy $[35,36]$. As this is still an early modality in the treatment of HCC, little has been published on HIFU in comparison to other ablative treatments. One study did compare TACE alone and in combination with HIFU. The combined group showed increased OS (overall survival) and disease-free survival [37]. More research is needed to truly consider the utility of HIFU in the treatment of HCC lesions.

Another novel ablation technique in the field of HCC treatment is laser ablation. Electrical energy is transformed into light energy, which causes target tissue to heat up and results in cell death [38]. One study by Ferrari et al. [39] showed that laser ablation, when compared with RFA, has similar OS and time to tumor recurrence. More research is needed in the areas of both laser ablation and HIFU in the treatment of HCC lesions moving forward. 


\section{Liver Cancer}

\section{Vascular Interventions}

The vasculature of HCC presents a unique treatment paradigm in that most of the lesions are perfused by the hepatic artery as compared to the rest of healthy liver tissue, which gets it supply from both the portal vein and the hepatic artery [40]. This presents a unique opportunity for transarterial vascular interventions in the treatment of HCC.

Hepatic artery infusion chemotherapy (HAIC) is available as a potential localized vascular intervention and consists of injecting high concentrations of chemotherapy via the hepatic artery in either bolus injections or continuous infusion [41]. A number of studies have shown survival benefits, though data are sparse and no randomized trials yet exist [42-44].

Bland hepatic artery embolization yields tumor tissue ischemia by using microspheres alone to embolize the vasculature perfusing the tumor tissue. In comparison studies that looked at bland embolization versus embolization with drug-eluting beads (DEB), Malagari et al. [45] showed that there was no significant difference in OS despite showing a decreased time to progression and improved response in the DEB group. Another randomized control trial showed no difference in response, progression, or OS when bland embolization was compared with chemoebolization [46].

TACE has long been held as one of the standards of care for HCC patients undergoing treatment. It is commonly used in intermediate-stage disease and has been proven in multiple studies to yield significant survival advantage [47-49]. The delivery of chemotherapy along with embolization of tumor vessels increases the concentration of drug delivered to the lesion and has the added benefit of decreasing systemic chemotherapy side effects [50].

Conventional TACE (CTACE) consists of delivering lipiodol along with the chemotherapy of choice, most commonly doxorubicin or cisplatin. Subsequently, the same vessel is embolized to disallow chemotherapy washout and to concurrently achieve ischemia of the tumor tissue (Fig. 2) [51]. Current European Association for the Study of Liver guidelines indicate that TACE is the current first-line therapy for patients with intermediate BCLC Stage B HCC [52]. Llovet and Bruix [49] showed that those patients receiving TACE had increased survival as compared to those receiving supportive therapy alone. TACE has also been used to downstage patients to within liver transplant criteria. Yao et al. [53, 54] looked at the use of LRTs, including TACE, and their success in downstaging patients to within transplant criteria and subsequent improved survival after transplant. The same group, in one study, showed that $70 \%$ of patients were able to be successfully downstaged using LRTs including TACE [54].

More recently, the development of DEB-TACE has become a more active field of research (Fig. 3). The main theory behind this technology is predicated on the concept that a longer and more sustained release of chemotherapy would yield better treatment results [55]. DEB-TACE also leads to fewer postembolization side effects than cTACE, less hepatic abscesses, and less doxorubicin-induced cardiotoxicity [56-59]. Multiple studies have evaluated the efficacy of cTACE compared to DEB-TACE with differing results. Lammer et al. [60] found a significant improvement of response rates in Child-Pugh score B patients and those patients with bilobar disease treated with DEB-TACE. Golfieri et al. [59] also demonstrated equal efficacy when DEB-TACE was compared with cTACE in a randomized control trial.

Transarterial radioembolization consists of embolization of target lesions via microspheres loaded with yttrium-90 (Y-90), a radioactive isotope [61]. This technique utilizes the same concept as chemoembolization in that the blood supply of HCC and the embolization of the tumor with beads loaded with radioactive isotopes allow for higher doses of radiation to be delivered directly to the target lesion. Radioembolization simultaneously decreases radiation dosing to the healthy liver tissue and surrounding structures [61-63]. Y-90 is most 

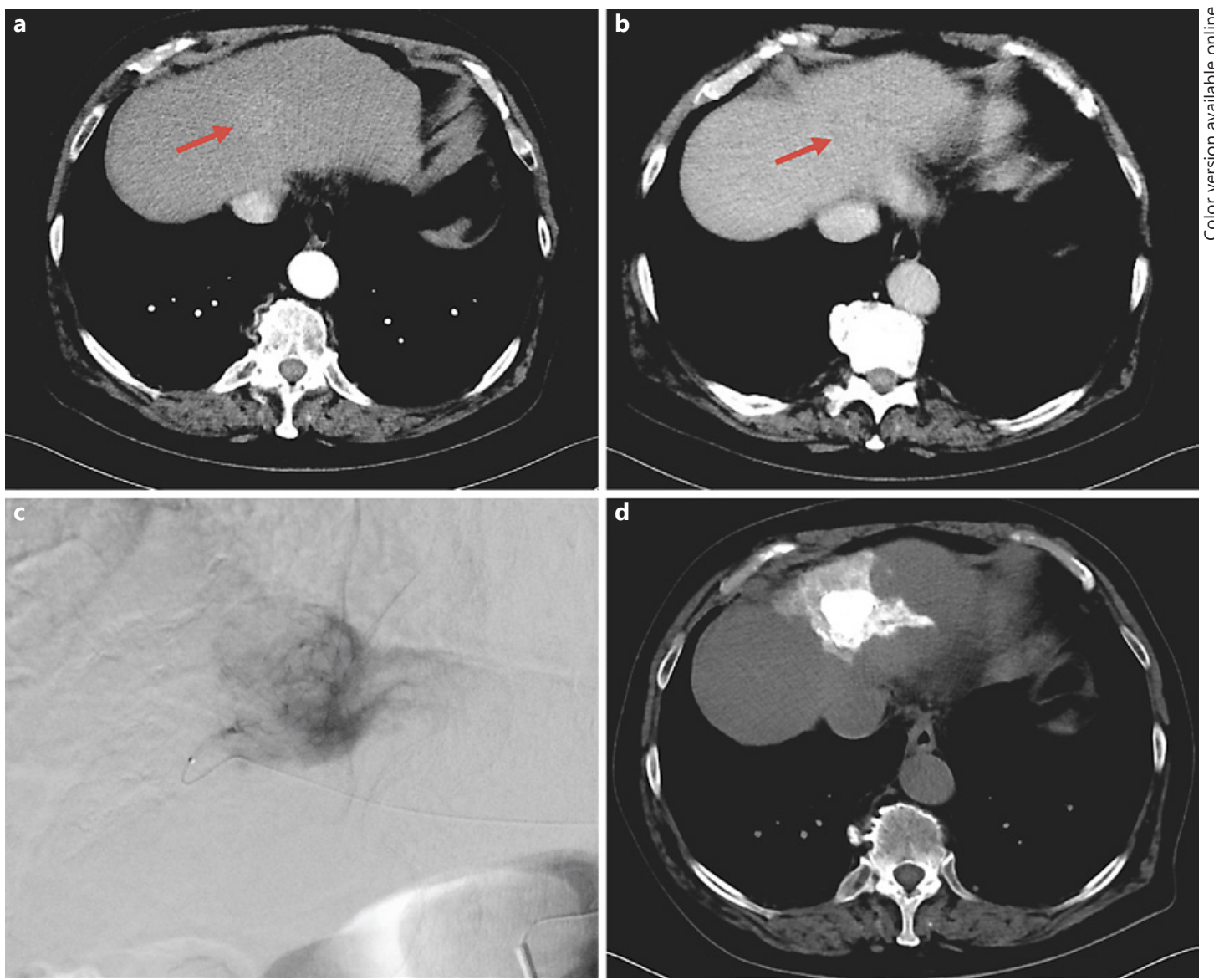

Fig. 2. CTACE in HCC. A 79-year-old patient with a hyperarterialized HCC lesion in the left liver lobe (a) with slight contrast agent washout in the venous phase (b). Highly selective cTACE of the tumor feeder artery was performed (c), and complete lipiodol saturation of the lesion was confirmed on same-day CT scan (d).

commonly utilized in advanced HCC and intermediate-HCC that are poor candidates for TACE or ablation; an example of a patient treated with this modality can be seen in Figure 4. One study utilizing Y-90 in HCC patients showed a significant difference in survival between ChildPugh A (17.2 months) compared to Child-Pugh B (7.7 months) [64]. Presence of portal vein thrombosis (PVT) was also shown to decrease survival times after radioembolization in this study [64]. Mazzaferro et al. [65] also looked at Y-90 treatment of intermediate or advanced HCC patients. The study showed a median time-to-progression of 11 months and showed no significant difference between PVT and no-PVT. One interesting study by Salem et al. [66] compared cTACE with Y-90 in intermediate HCC patients. Time to progression was significantly longer in the $\mathrm{Y}-90$ cohort. A recent meta-analysis showed that $\mathrm{Y}-90$ yielded significant improvement in OS and time-to-progression when compared to TACE [67]. The use of sorafenib in locally advanced HCC has also been compared with Y-90 in this patient population. Both the SARAH and SIRveNIB trials compared radioembolization with sorafenib and showed that there was no significant difference in OS between the two treatment methods $[68,69]$. 

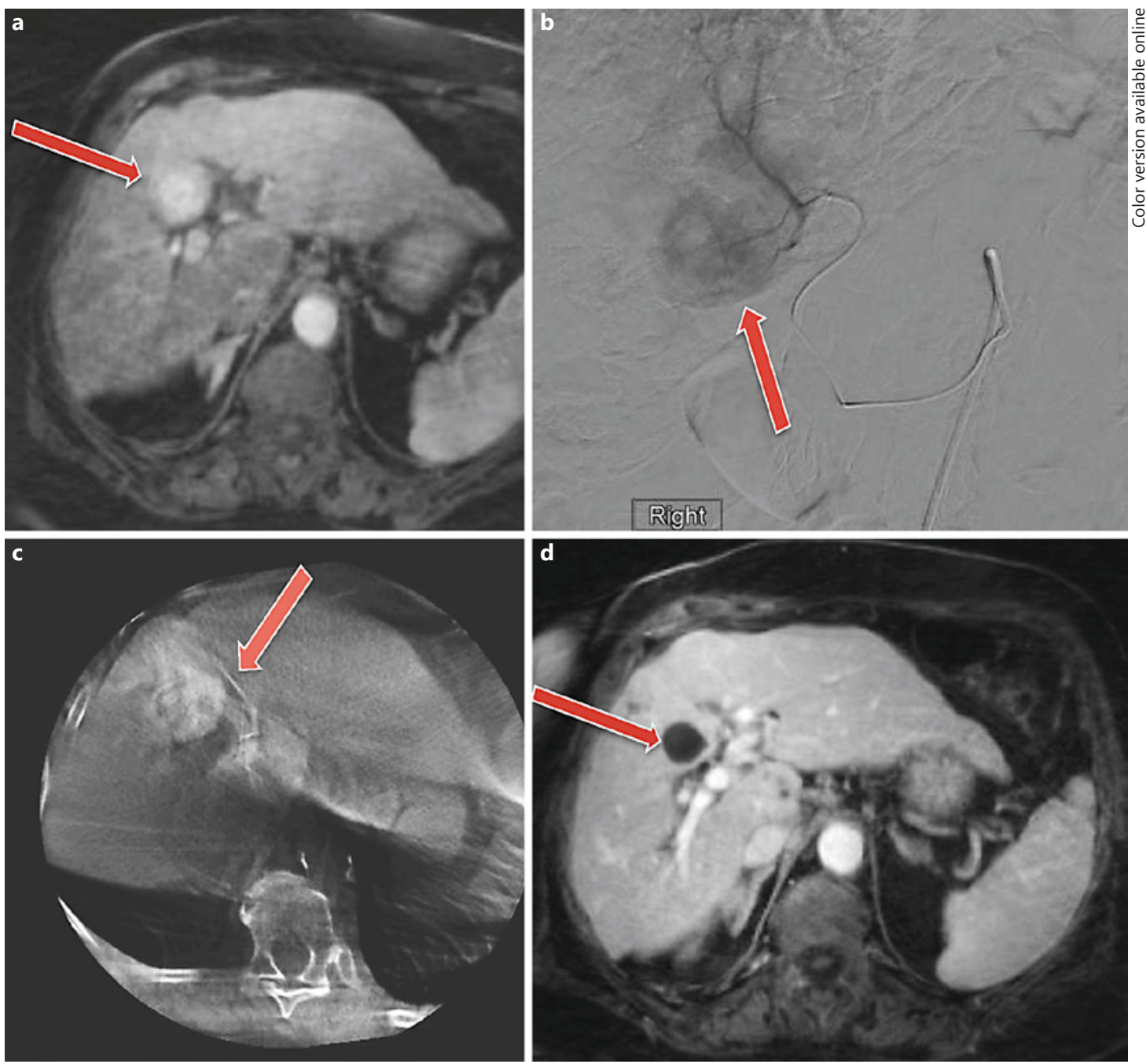

Fig. 3. DEB-TACE in HCC. A 94-year-old patient with nonalcoholic steatohepatitis who developed a solitary HCC on MRI (a) and angiography (b). c Posttreatment cone beam CT confirmed DEB deposition (DC Bead ${ }^{\circledR}$ ) within the tumor. $\mathbf{d}$ Three-month posttreatment follow-up demonstrated complete response.

\section{Combination Therapies}

The combination of local and systemic therapies has been studied to assess for increased response rates and OS benefit. Sorafenib, the most commonly used and FDA-approved systemic chemotherapy regimen for advanced HCC, has been considered in conjunction with LRTs $[70,71]$. One study looked at the utility of combining sorafenib with Y-90 radioembolization in HCC patients. The study showed a median OS of 19.5 months, which is an improvement when compared to those patients treated with sorafenib alone in similarly designed studies [72]. Park et al. [73] looked at the combination of TACE and sorafenib and determined that the overall time-to-progression was 7.1 months, and that the median OS rate was 20.8 months. A study by Pawlik et al. [74] explored the safety of DEB-TACE in conjunction with sorafenib and deemed the combined treatment to be similar to the safety of sorafenib alone, as most side effects were related to sorafenib dosing. 


\section{Liver Cancer}

\begin{tabular}{l|l}
\hline Liver Cancer 2019;8:326-340 \\
\hline DOI: 10.1159/000494843 & $\begin{array}{l}\text { ○ } 2019 \text { S. Karger AG, Basel } \\
\text { www.karger.com/lic }\end{array}$ \\
\hline
\end{tabular}

Dendy et al.: Locoregional Therapy, Immunotherapy and the Combination in HCC
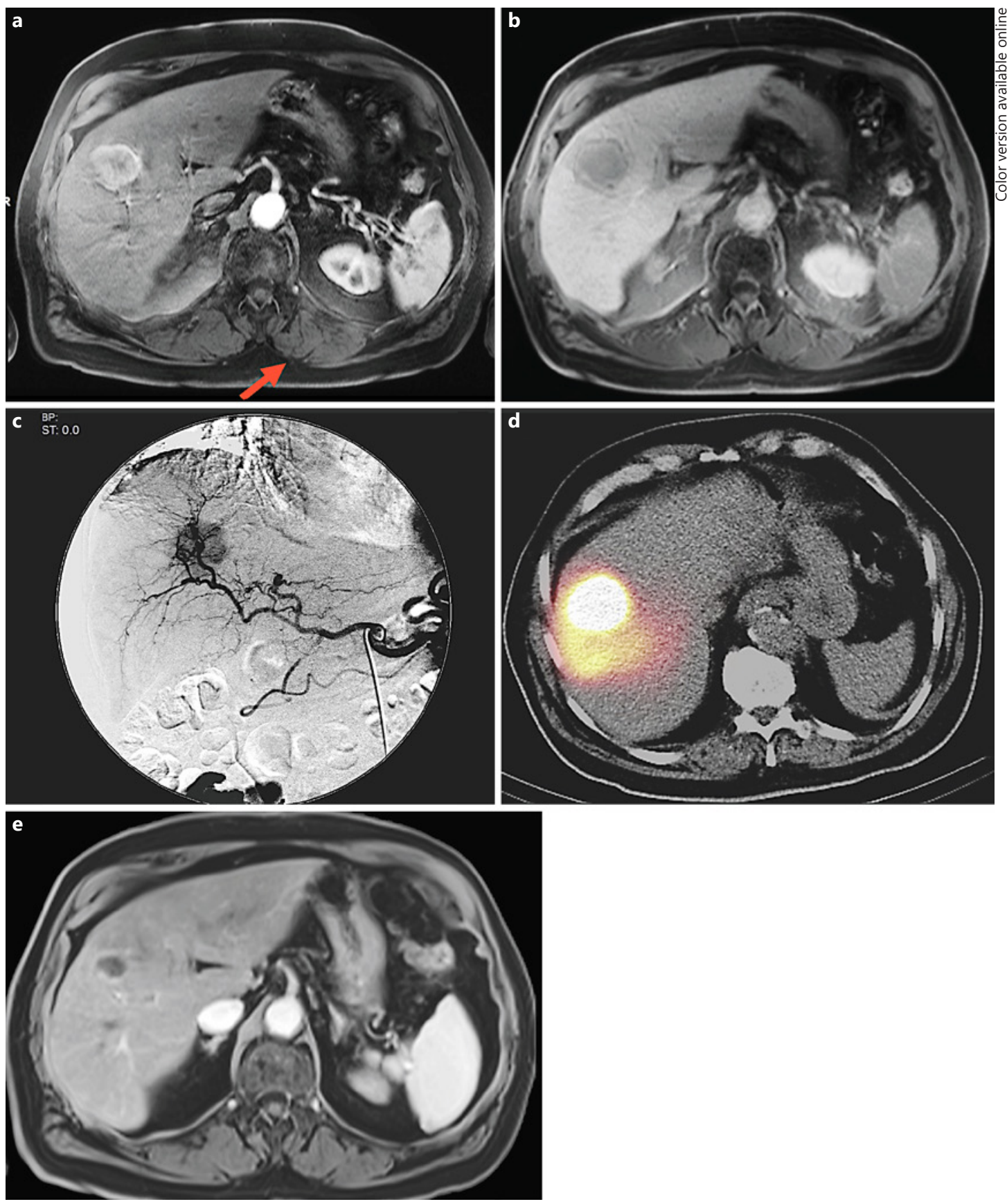

Fig. 4. ${ }^{90}$ Y-radioembolization in HCC. A 78-year-old patient with a lesion suspicious for HCC in the right liver lobe, supplied by arteries from the liver segments 8 and 4. T1-weighted MRI gradient echo imaging with contrast enhancement shows increased arterial enhancement (a) and venous washout on MRI (b). c Similarly, angiography demonstrated hypervascularity. Tc99m MAA (macroaggregated albumin) was injected into the cranial vessel of the right hepatic artery after embolizing the liver segment 4 artery to achieve redistribution of the arterial blood supply. $\mathbf{d}$ Relatively selective Tc99m MAA delivery to the entire lesion was achieved as shown in SPECT/CT. e Three-month follow-up demonstrated size reduction of the partial necrotic lesion on T1-weighted MR gradient echo imaging with contrast enhancement. 


\section{Liver
Cancer}

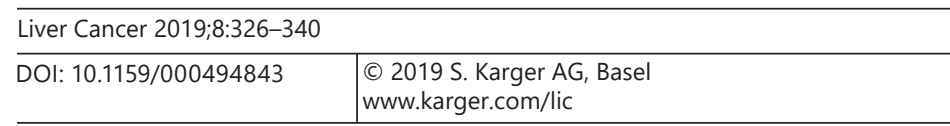

Dendy et al.: Locoregional Therapy, Immunotherapy and the Combination in HCC

Multiple studies evaluating the use of ablation in combination with transarterial therapies have been completed. Morimoto et al. [75] studied 37 patients with intermediate HCCs and showed that those patients receiving combination RFA and TACE had decreased local tumor progression rates. Veltri et al. [76] assessed survival in 51 lesions treated with RFA after TACE, yielding an 89.7\% survival at 1-year follow-up. Lencioni et al. [77] studied 20 HCC patients treated with RFA followed by DEB-TACE and yielded a $60 \%$ complete response rate after both therapies were administered.

There have also been a few studies that looked at the combination of HAIC with systemic therapy, though the data are conflicting and sparser. A randomized phase II trial completed by Ikeda et al. [78] showed an increased median survival in the group that received systemic sorafenib and HAIC with cisplatin as compared to sorafenib alone (10.6 vs. 8.7 months, $p=0.031$ ). However, the SILIUS study showed no improvement in median OS in a phase III randomized clinical trial comparing sorafenib alone with sorafenib plus HAIC [79].

\section{Future Directions of LRTs}

The overall 5-year survival of patients with liver cancer in the US has increased from 5\% in 1987-1989 to 18\% in 2005-2011 [80]. Substantial contribution to this improvement can be attributed to the development and establishment of LRTs, as discussed in the sections above, which are still lagging behind initial expectations. Therefore, new and more efficient treatment approaches are absolutely warranted to further improve treatment outcomes. In the following section a brief overview of potential new approaches will be outlined.

\section{DEB: Beyond Loading of Conventional Antineoplastic Drugs}

Drug delivery via DEB increases intratumoral drug accumulation for a prolonged period of time while limiting systemic drug exposure and side effects compared to systemic administration [81]. These compelling pharmacokinetics have sparked interest in the research community to go beyond loading of conventional chemotherapeutic agents.

\section{Loading of Tyrosine Kinase Inhibitors}

To date, several tyrosine kinase inhibitors (TKIs) have been successfully loaded on the widely clinically used DC Bead ${ }^{\circledR}$ (BTG, London, UK) in preclinical studies. The multitargeted TKI sunitinib has been demonstrated to rapidly load onto DEB with an elution half-life time of 1.1-1.6 h for 70-150 and 100-300 $\mu \mathrm{m}$ DEB, respectively. A total elution of up to $~ 80 \%$ in vitro has been reported, which would potentially allow for higher intratumoral concentrations than achieved by systemic administration $[82,83]$. This is especially interesting considering the observed direct cytotoxic effect observed in Hep G2 cells when coincubated with sunitinib-loaded DC Bead ${ }^{\circledR}$ in vitro [82]. In vivo testing in New Zealand white rabbits has demonstrated high intrahepatic sunitinib concentration with relatively low drug plasma level, again indicating its potential use in HCC therapy [83]. In a follow-up study, intra-arterial injection of sunitinib DEB demonstrated tumor growth arrest within 2 weeks, while oral sunitinib therapy and bland DEB (embolization with unloaded beads) injection demonstrated a tumor growth of $+1,583 \%$ and $+42 \%$, respectively [84].

Vandetanib, a multi-TKI of VEGFR tumor angiogenesis and EGFR \& RET-dependent inhibitor of proliferation, could be loaded onto both conventional DC Bead ${ }^{\circledR}$ and the radi- 


\section{Liver

Dendy et al.: Locoregional Therapy, Immunotherapy and the Combination in HCC

opaque DC Bead LUMI ${ }^{\mathrm{TM}}$ with 30 and $135 \mathrm{mg} / \mathrm{mL}$, respectively. In vitro eluting mostly occurred within the first $2 \mathrm{~h}$ with slightly more than 40 and $80 \%$ of the loaded amount for DC Bead ${ }^{\circledR}$ and the radiopaque DC Bead LUMI ${ }^{\mathrm{TM}}$, respectively [85]. In a healthy porcine model, vandetanib DEB-TACE of the liver was well tolerated and was shown to achieve therapeutic concentrations for up to 30 days after administration with low systemic spillage [86].

\section{Loading of Bevacizumab}

In in vitro experiments, Sakr et al. [87] managed to coat the anti-VEGF antibody bevacizumab in high amounts on DC Bead ${ }^{\circledR}$, while mostly preserving the biologic activity after its release in vitro. Yet, further studies in vivo are warranted to test stability and treatment effect.

\section{Loading with Newly Designed Targeted Drug Compounds}

With the development of the targeted drug compound SW43-DOX, a different approach at improving treatment efficacy has been taken. SW43-DOX is composed of the chemotherapeutic agent doxorubicin and the sigma-2 receptor agonist SW43 [88]. The sigma-2 receptor is overexpressed in many cancer types including pancreatic cancer, colorectal carcinoma, breast cancer, lung cancer, and melanoma as well as in HCC. Aside from allowing for HCC targeting, SW43 also exerts a profound antineoplastic treatment effect which synergistically acts with antineoplastic drugs such as doxorubicin and exceeds the treatment effect of either drug alone [88-90]. Moreover, via the doxorubicin moiety, the compound can be easily loaded onto DEB for intra-arterial tumor delivery [88]. In one study, SW43-DOX was complemented with the chelator L-NETA and therefore suitable for loading several radioisotopes such as, e.g., Lutetium ${ }^{177}$ and Yttrium ${ }^{90 / 89}$ [91]. When loaded onto DEB, this drug compound embodies the concept of a "Targeted Radiochemoembolization Drug-Eluting Bead" therapy which combines four modes of antineoplastic actions: (A) hypoxic cell death via DEB vessel occlusion, (B) cancer targeting and cell death induction via SW43, (C) doxorubicin as antineoplastic agent, and (D) radiation therapy. Preliminary safety evaluations with SW43-DOX-LNETA $\left({ }^{89} \mathrm{Y}\right)$-DEB in rabbits bearing VX2 liver tumors demonstrated its feasibility and safety as well as indicated its positive treatment effects [91].

Overall, loading DC Bead ${ }^{\circledR}$ with TKIs, bevacizumab, or targeted drug compounds broadens the spectrum of treatment opportunities for DEB-TACE. In addition to the above-discussed advances using DC Bead ${ }^{\circledR}$, various other embolic microspheres and beads for the treatment of HCC have been discussed in depth in a recent review by Fuchs et al. [81].

\section{Immunotherapeutics: A New Direction for LRTs}

For immunotherapy, HCC is an attractive target due to its immunological properties such as chronic inflammation, immunosuppressive environment, and immune evasion [92].

\section{Oncolytic Viruses}

Despite many tested oncolytic viruses (OVs) in preclinical studies, only a few have successfully made it into clinical trials, with JX-594 (Pexa-Vec; Jennerex Inc.) being the best studied in HCC. JX-594 is a modified poxvirus with an inserted human granulocyte-macrophage colony-stimulating factor (hGM-CSF) gene. The mode of action does not only involve direct cell lysis of invaded cancer cells but also stimulates an anticancer immune response by (A) making tumor antigens abundantly available and (B) modifying immune response by expression of hGM-CSF [92-95]. JX-594 can be injected intravascularly or directly into the tumor. In clinical studies, JX-594 demonstrated high tolerability with hyperbilirubi- 


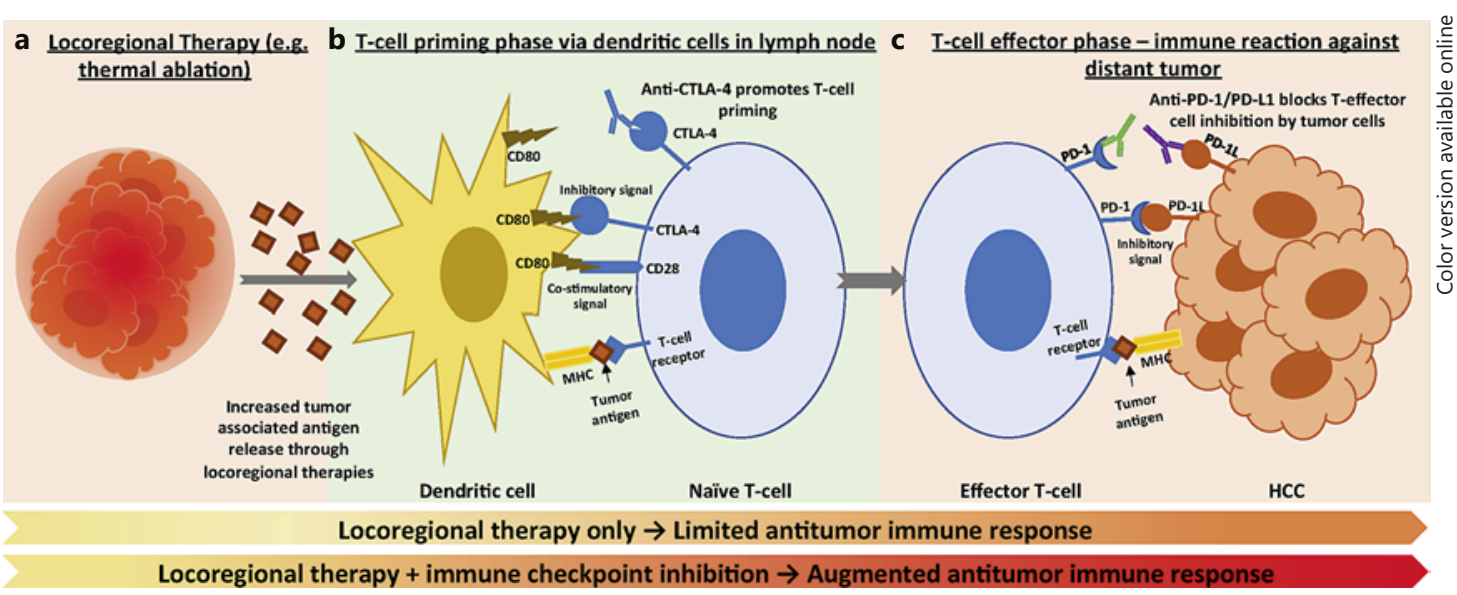

Fig. 5. Combination of locoregional therapies with immune checkpoint inhibitors augments anti-tumor immune response. Locoregional therapy alone only induces a weak and transient antitumor immune response, usually not resulting in a significant antitumoral treatment effect. The combination with immune checkpoint inhibitors reciprocally augments the overall antitumor immune response. Simplified, locoregional therapies increase availability of tumor-associated antigens (a), anti-CTLA-4 promotes T-cell priming in lymph nodes by blocking the inhibitory signal on T-cell priming (CD80 \& CTLA-4 surface proteins) (b), and anti-PD-1/PDL1 antibodies block the immune inhibitory signal from cancer cells on immune cells (c).

nemia as the limiting toxicity factor (maximum tolerated dose: $1 \times 10^{9}$ plaque-forming units [PFU]) [94]. It showed induction of antivascular cytokines and suppressed HBV replication and a statistically prolonged median survival for higher treatment doses (high dose $\left[10^{9}\right.$ PFU] vs. low dose [ $\left.10^{8} \mathrm{PFU}\right]: 14.1$ vs. 6.7 months, $p=0.02$ ) [94]. Interestingly, intrahepatic tumor control (50\%) was similar in injected and noninjected tumors at both doses, demonstrating a systemic treatment effect after LRT [93]. JX-594 and sorafenib have a complimentary mode of action, which was investigated in a 3-patient pilot study, where sorafenib was given after failure of JX-549 therapy. In all 3 patients, stable disease was achieved with sorafenib [95].

Currently, several studies are underway investigating JX-549 in sorafenib-naïve patients (NCT01636284), after failure of sorafenib therapy (NCT01387555), in combination with sorafenib (NCT02562755), or in combination with nivolumab (NCT03071094).

Talimogene laherparepvec (T-VEC, Amgen), another OV, was approved for unresectable stages of melanoma (Stage IIIB/C and IV) in October 2015. A phase I study in patients with HCC and liver metastases where T-VEC is injected directly into the liver lesions is currently underway (NCT02509507). Apart from OVs, many other, mostly systemic, immunotherapeutic approaches including, e.g., dendritic cells are being tested and have been discussed in depth in a recent review [96].

\section{Immune Checkpoint Inhibitors in Combination with LRTs}

In recent years, cancer treatment with antibodies targeting CTLA-4 and/or PD-1/PD-L1 surface proteins alone or in combination have emerged as a promising treatment approach in patients with metastatic disease by stimulating an effective systemic immune response against tumor cells. Several studies have reported promising partial response rates since approval of nivolumab by the US Food and Drug Administration as a second-line therapy for HCC. Reports have shown partial response rates ranging from 14.8 to $26.3 \%$ in addition to disease control rates ranging from 62.5 to $81.8 \%$ [97-102]. Currently ongoing randomized 


\section{Liver Cancer}

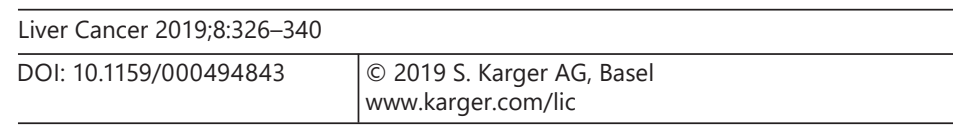

Dendy et al.: Locoregional Therapy, Immunotherapy and the Combination in HCC

control trials are looking into the efficacy of nivolumab as a first-line therapy when compared to sorafenib [103].

LRTs such as TACE, selective internal radiation therapy (SIRT), and thermal ablation can increase tumor immunogenicity by inducing inflammation and by releasing increased amounts of tumor-associated antigens, which can result in an increased systemic antitumor immune response with tumor infiltrating cytotoxic CD8+ T cells. However, the observed antitumoral treatment effect of LRTs alone is usually negligible and only led to significant tumor regression in several reported cases [97, 101, 104, 105].

In several preclinical studies, the combination of LRTs with immune checkpoint inhibitors has demonstrated increased antitumor immune response (Fig. 5), making it a promising combination [104]. A recent study in humans evaluated the combined treatment efficacy of the anti-CTLA-4 antibody tremelimumab together with either subtotal TACE (BCLC B patients) or thermal ablation (BCLC C patients). Here, the partial response rate was $26.3 \%$, the median time to progression was 7.4 months, and the median OS was 12.3 months. Six-week tumor biopsies in responding lesions not treated by LRTs demonstrated a significant increase in CD3+ and CD8+ immune cell infiltration compared to nonresponding lesions. Moreover, $85.7 \%$ of patients with active HCV infection experienced a marked reduction in viral load [99]. Currently, several studies are underway evaluating the combination of nivolumab with SIRT (NCT03380130, NCT03033446, 02837029), pembrolizumab with SIRT (NCT03099564), and nivolumab with TACE (NCT03143270).

\section{Conclusion}

Despite the treatment success of current LRTs, development of new drugs and treatment approaches as well as the combination of LRTs with systemic therapies may further improve response and OS rates in HCC treatment. Initial results from studies combining conventional LRTs with immunotherapies demonstrated especially promising results, with several active studies being greatly anticipated. Also, the increasing number of available therapies may offer the opportunity to better tailor treatment approaches to patients according to the etiopathology (e.g., viral vs. nonviral) as well as the physical performance status and remaining liver function of patients. Overall, new study results will most likely result in a paradigm shift, definitively changing the current conventional treatment algorithms of HCC therapy.

\section{Disclosure Statement}

The authors certify that all authors have no relevant financial conflict of interest for any aspect of the submitted manuscript. The authors certify that no authors at any time received payment or services from a third party for any aspect of the submitted manuscript. H.S.K. served on Advisory boards for Boston Scientific and SIRTex.

\section{Funding Sources}

H.S.K. is supported by the United States Department of Defense (CA160741). 
Dendy et al.: Locoregional Therapy, Immunotherapy and the Combination in HCC

\section{References}

1 Jemal A, Bray F, Center MM, Ferlay J, Ward E, Forman D. Global cancer statistics. CA Cancer J Clin. 2011 Mar-Apr;61(2):69-90.

2 El-Serag HB. Epidemiology of viral hepatitis and hepatocellular carcinoma. Gastroenterology. 2012 May; 142(6):1264-1273.e1.

3 Grieco A, Pompili M, Caminiti G, Miele L, Covino M, Alfei B, et al. Prognostic factors for survival in patients with early-intermediate hepatocellular carcinoma undergoing non-surgical therapy: comparison of Okuda, CLIP, and BCLC staging systems in a single Italian centre. Gut. 2005 Mar;54(3):411-8.

4 Sørensen JB, Klee M, Palshof T, Hansen HH. Performance status assessment in cancer patients. An interobserver variability study. Br J Cancer. 1993 Apr;67(4):773-5.

5 Mazzaferro V, Regalia E, Doci R, Andreola S, Pulvirenti A, Bozzetti F, et al. Liver transplantation for the treatment of small hepatocellular carcinomas in patients with cirrhosis. N Engl J Med. 1996 Mar;334(11): 693-9.

6 Sangro B, Iñarrairaegui M, Bilbao JI. Radioembolization for hepatocellular carcinoma. J Hepatol. 2012 Feb; 56(2):464-73.

7 Huang J, Yan L, Cheng Z, Wu H, Du L, Wang J, et al. A randomized trial comparing radiofrequency ablation and surgical resection for HCC conforming to the Milan criteria. Ann Surg. 2010 Dec;252(6):903-12.

8 Shen A, Zhang H, Tang C, Chen Y, Wang Y, Zhang C, et al. Systematic review of radiofrequency ablation versus percutaneous ethanol injection for small hepatocellular carcinoma up to $3 \mathrm{~cm}$. J Gastroenterol Hepatol. 2013 May;28(5):793-800.

9 Liu Z, Zhou Y, Zhang P, Qin H. Meta-analysis of the therapeutic effect of hepatectomy versus radiofrequency ablation for the treatment of hepatocellular carcinoma. Surg Laparosc Endosc Percutan Tech. 2010 Jun;20(3): 130-40.

10 Zhou Y, Zhao Y, Li B, Xu D, Yin Z, Xie F, et al. Meta-analysis of radiofrequency ablation versus hepatic resection for small hepatocellular carcinoma. BMC Gastroenterol. 2010 Jul;10(1):78.

11 McGahan JP, Browning PD, Brock JM, Tesluk H. Hepatic ablation using radiofrequency electrocautery. Invest Radiol. 1990 Mar;25(3):267-70.

12 Livraghi T, Solbiati L, Meloni MF, Gazelle GS, Halpern EF, Goldberg SN. Treatment of focal liver tumors with percutaneous radio-frequency ablation: complications encountered in a multicenter study. Radiology. 2003 Feb;226(2):441-51.

13 Bruix J, Sherman M; American Association for the Study of Liver Diseases. Management of hepatocellular carcinoma: an update. Hepatology. 2011 Mar;53(3):1020-2.

14 Lencioni R. Loco-regional treatment of hepatocellular carcinoma. Hepatology. 2010 Aug; 52(2):762-73.

15 Livraghi T, Bolondi L, Lazzaroni S, Marin G, Morabito A, Rapaccini GL, et al. Percutaneous ethanol injection in the treatment of hepatocellular carcinoma in cirrhosis. A study on 207 patients. Cancer. 1992 Feb;69(4):925-9.

16 Permpongkosol S, Nicol TL, Khurana H, Link RE, Zhai QJ, Kavoussi LR, et al. Thermal maps around two adjacent cryoprobes creating overlapping ablations in porcine liver, lung, and kidney. J Vasc Interv Radiol. 2007 Feb; 18(2):283-7.

17 Fairchild AH, Tatli S, Dunne RM, Shyn PB, Tuncali K, Silverman SG. Percutaneous cryoablation of hepatic tumors adjacent to the gallbladder: assessment of safety and effectiveness. J Vasc Interv Radiol. 2014 Sep; 25(9):1449-55.

18 Huang YZ, Zhou SC, Zhou H, Tong M. Radiofrequency ablation versus cryosurgery ablation for hepatocellular carcinoma: a meta-analysis. Hepatogastroenterology. 2013 Jul-Aug;60(125):1131-5.

19 Wang C, Wang H, Yang W, Hu K, Xie H, Hu KQ, et al. Multicenter randomized controlled trial of percutaneous cryoablation versus radiofrequency ablation in hepatocellular carcinoma. Hepatology. 2015;61(5):15791590.

20 Chen HW, Lai EC, Zhen ZJ, Cui WZ, Liao S, Lau WY. Ultrasound-guided percutaneous cryotherapy of hepatocellular carcinoma. Int J Surg. 2011;9(2):188-91.

21 Lubner MG, Brace CL, Hinshaw JL, Lee FT Jr. Microwave tumor ablation: mechanism of action, clinical results, and devices. J Vasc Interv Radiol. 2010 Aug;21(8 Suppl):S192-203.

22 Liang P, Wang Y. Microwave ablation of hepatocellular carcinoma. Oncology. 2007;72 Suppl 1:124-31.

23 He N, Wang W, Ji Z, Li C, Huang B. Microwave ablation: an experimental comparative study on internally cooled antenna versus non-internally cooled antenna in liver models. Acad Radiol. 2010 Jul;17(7):894-9.

24 Liang P, Yu J, Yu XL, Wang XH, Wei Q, Yu SY, et al. Percutaneous cooled-tip microwave ablation under ultrasound guidance for primary liver cancer: a multicentre analysis of 1363 treatment-naive lesions in 1007 patients in China. Gut. 2012 Jul;61(7):1100-1.

25 Fan ST, Mau Lo C, Poon RT, Yeung C, Leung Liu C, Yuen WK, et al. Continuous improvement of survival outcomes of resection of hepatocellular carcinoma: a 20-year experience. Ann Surg. 2011 Apr;253(4):745-58.

26 Shi J, Sun Q, Wang Y, Jing X, Ding J, Yuan Q, et al. Comparison of microwave ablation and surgical resection for treatment of hepatocellular carcinomas conforming to Milan criteria. J Gastroenterol Hepatol. 2014;29(7): 1500-7.

27 Takami Y, Ryu T, Wada Y, Saitsu H. Evaluation of intraoperative microwave coagulo-necrotic therapy (MCN) for hepatocellular carcinoma: a single center experience of 719 consecutive cases. J Hepatobiliary Pancreat Sci. 2013 Mar;20(3):332-41. 
28 Zhang L, Wang N, Shen Q, Cheng W, Qian GJ. Therapeutic efficacy of percutaneous radiofrequency ablation versus microwave ablation for hepatocellular carcinoma. PLoS One. 2013 Oct;8(10):e76119.

29 Potretzke TA, Ziemlewicz TJ, Hinshaw JL, Lubner MG, Wells SA, Brace CL, et al. Microwave versus Radiofrequency Ablation Treatment for Hepatocellular Carcinoma: A Comparison of Efficacy at a Single Center. J Vasc Interv Radiol. 2016 May;27(5):631-8.

30 Savic LJ, Chapiro J, Hamm B, Gebauer B, Collettini F. Irreversible Electroporation in Interventional Oncology: Where We Stand and Where We Go. Rofo. 2016 Aug;188(8):735-45.

31 Silk MT, Wimmer T, Lee KS, Srimathveeravalli G, Brown KT, Kingham PT, et al. Percutaneous ablation of peribiliary tumors with irreversible electroporation. J Vasc Interv Radiol. 2014 Jan;25(1):112-8.

32 Cannon R, Ellis S, Hayes D, Narayanan G, Martin RC 2nd. Safety and early efficacy of irreversible electroporation for hepatic tumors in proximity to vital structures. J Surg Oncol. 2013 Apr;107(5):544-9.

33 Cheung W, Kavnoudias H, Roberts S, Szkandera B, Kemp W, Thomson KR. Irreversible electroporation for unresectable hepatocellular carcinoma: initial experience and review of safety and outcomes. Technol Cancer Res Treat. 2013 Jun;12(3):233-41.

34 Thomson KR, Cheung W, Ellis SJ, Federman D, Kavnoudias H, Loader-Oliver D, et al. Investigation of the safety of irreversible electroporation in humans. J Vasc Interv Radiol. 2011 May;22(5):611-21.

35 Diana M, Schiraldi L, Liu YY, Memeo R, Mutter D, Pessaux P, et al. High intensity focused ultrasound (HIFU) applied to hepato-bilio-pancreatic and the digestive system-current state of the art and future perspectives. Hepatobiliary Surg Nutr. 2016 Aug;5(4):329-44.

36 Shen HP, Gong JP, Zuo GQ. Role of high-intensity focused ultrasound in treatment of hepatocellular carcinoma. Am Surg. 2011 Nov;77(11):1496-501.

37 Li C, Zhang W, Zhang R, Zhang L, Wu P, Zhang F. Therapeutic effects and prognostic factors in high-intensity focused ultrasound combined with chemoembolisation for larger hepatocellular carcinoma. Eur J Cancer. 2010 Sep;46(13):2513-21.

38 Di Costanzo GG, Francica G, Pacella CM. Laser ablation for small hepatocellular carcinoma: state of the art and future perspectives. World J Hepatol. 2014 Oct;6(10):704-15.

39 Ferrari FS, Megliola A, Scorzelli A, Stella A, Vigni F, Drudi FM, et al. Treatment of small HCC through radiofrequency ablation and laser ablation. Comparison of techniques and long-term results. Radiol Med (Torino). 2007 Apr;112(3):377-93.

40 Chuang VP, Wallace S. Hepatic artery embolization in the treatment of hepatic neoplasms. Radiology. 1981 Jul 140(1):51-8.

41 Obi S, Sato S, Kawai T. Current Status of Hepatic Arterial Infusion Chemotherapy. Liver Cancer. 2015 Sep;4(3): 188-99.

42 Nouso K, Miyahara K, Uchida D, Kuwaki K, Izumi N, Omata M, et al.; Liver Cancer Study Group of Japan. Effect of hepatic arterial infusion chemotherapy of 5-fluorouracil and cisplatin for advanced hepatocellular carcinoma in the Nationwide Survey of Primary Liver Cancer in Japan. Br J Cancer. 2013 Oct;109(7):1904-7.

43 Ueshima K, Kudo M, Takita M, Nagai T, Tatsumi C, Ueda T, et al. Hepatic arterial infusion chemotherapy using low-dose 5-fluorouracil and cisplatin for advanced hepatocellular carcinoma. Oncology. 2010 Jul; 78 Suppl 1: 148-53.

44 Sakon M, Nagano H, Dono K, Nakamori S, Umeshita K, Yamada A, et al. Combined intraarterial 5-fluorouracil and subcutaneous interferon-alpha therapy for advanced hepatocellular carcinoma with tumor thrombi in the major portal branches. Cancer. 2002 Jan;94(2):435-42.

45 Malagari K, Pomoni M, Kelekis A, Pomoni A, Dourakis S, Spyridopoulos T, et al. Prospective randomized comparison of chemoembolization with doxorubicin-eluting beads and bland embolization with BeadBlock for hepatocellular carcinoma. Cardiovasc Intervent Radiol. 2010 Jun;33(3):541-51.

46 Brown KT, Do RK, Gonen M, Covey AM, Getrajdman GI, Sofocleous CT, et al. Randomized Trial of Hepatic Artery Embolization for Hepatocellular Carcinoma Using Doxorubicin-Eluting Microspheres Compared With Embolization With Microspheres Alone. J Clin Oncol. 2016 Jun;34(17):2046-53.

47 Cammà C, Schepis F, Orlando A, Albanese M, Shahied L, Trevisani F, et al. Transarterial chemoembolization for unresectable hepatocellular carcinoma: meta-analysis of randomized controlled trials. Radiology. 2002 Jul; 224(1):47-54.

48 Llovet JM, Real MI, Montaña X, Planas R, Coll S, Aponte J, et al.; Barcelona Liver Cancer Group. Arterial embolisation or chemoembolisation versus symptomatic treatment in patients with unresectable hepatocellular carcinoma: a randomised controlled trial. Lancet. 2002 May;359(9319):1734-9.

49 Llovet JM, Bruix J. Systematic review of randomized trials for unresectable hepatocellular carcinoma: chemoembolization improves survival. Hepatology. 2003 Feb;37(2):429-42.

50 Anderson JH, Gianturco C, Wallace S. Experimental transcatheter intraarterial infusion-occlusion chemotherapy. Invest Radiol. 1981 Nov-Dec;16(6):496-500.

51 Nakamura H, Hashimoto T, Oi H, Sawada S. Transcatheter oily chemoembolization of hepatocellular carcinoma. Radiology. 1989 Mar;170(3 Pt 1):783-6.

52 Sacco R, Tapete G, Simonetti N, Sellitri R, Natali V, Melissari S, et al. Transarterial chemoembolization for the treatment of hepatocellular carcinoma: a review. J Hepatocell Carcinoma. 2017 Jul;4:105-10.

53 Yao FY, Kinkhabwala M, LaBerge JM, Bass NM, Brown R Jr, Kerlan R, et al. The impact of pre-operative locoregional therapy on outcome after liver transplantation for hepatocellular carcinoma. Am J Transplant. 2005 Apr;5(4 Pt 1):795-804. 
Dendy et al.: Locoregional Therapy, Immunotherapy and the Combination in HCC

54 Yao FY, Hirose R, LaBerge JM, Davern TJ 3rd, Bass NM, Kerlan RK Jr, et al. A prospective study on downstaging of hepatocellular carcinoma prior to liver transplantation. Liver Transpl. 2005 Dec;11(12):1505-14.

55 Lewis AL, Gonzalez MV, Lloyd AW, Hall B, Tang Y, Willis SL, et al. DC bead: in vitro characterization of a drugdelivery device for transarterial chemoembolization. J Vasc Interv Radiol. 2006 Feb;17(2 Pt 1):335-42.

56 Lo CM, Ngan H, Tso WK, Liu CL, Lam CM, Poon RT, et al. Randomized controlled trial of transarterial lipiodol chemoembolization for unresectable hepatocellular carcinoma. Hepatology. 2002 May;35(5):1164-71.

57 Varela M, Real MI, Burrel M, Forner A, Sala M, Brunet M, et al. Chemoembolization of hepatocellular carcinoma with drug eluting beads: efficacy and doxorubicin pharmacokinetics. J Hepatol. 2007 Mar;46(3):474-81.

58 Song MJ, Chun HJ, Song DS, Kim HY, Yoo SH, Park CH, et al. Comparative study between doxorubicin-eluting beads and conventional transarterial chemoembolization for treatment of hepatocellular carcinoma. J Hepatol. 2012 Dec;57(6):1244-50.

59 Golfieri R, Giampalma E, Renzulli M, Cioni R, Bargellini I, Bartolozzi C, et al.; PRECISION ITALIA STUDY GROUP. Randomised controlled trial of doxorubicin-eluting beads vs conventional chemoembolisation for hepatocellular carcinoma. Br J Cancer. 2014 Jul;111(2):255-64.

60 Lammer J, Malagari K, Vogl T, Pilleul F, Denys A, Watkinson A, et al.; PRECISION V Investigators. Prospective randomized study of doxorubicin-eluting-bead embolization in the treatment of hepatocellular carcinoma: results of the PRECISION V study. Cardiovasc Intervent Radiol. 2010 Feb;33(1):41-52.

61 Morgan B, Kennedy AS, Lewington V, Jones B, Sharma RA. Intra-arterial brachytherapy of hepatic malignancies: watch the flow. Nat Rev Clin Oncol. 2011 Feb;8(2):115-20.

62 Lewandowski RJ, Sato KT, Atassi B, Ryu RK, Nemcek AA Jr, Kulik L, et al. Radioembolization with 90Y microspheres: angiographic and technical considerations. Cardiovasc Intervent Radiol. 2007 Jul-Aug;30(4):571-92.

63 Salem R, Lewandowski RJ, Sato KT, Atassi B, Ryu RK, Ibrahim S, et al. Technical aspects of radioembolization with 90Y microspheres. Tech Vasc Interv Radiol. 2007 Mar;10(1):12-29.

64 Salem R, Lewandowski RJ, Mulcahy MF, Riaz A, Ryu RK, Ibrahim S, et al. Radioembolization for hepatocellular carcinoma using Yttrium-90 microspheres: a comprehensive report of long-term outcomes. Gastroenterology. 2010 Jan;138(1):52-64.

65 Mazzaferro V, Sposito C, Bhoori S, Romito R, Chiesa C, Morosi C, et al. Yttrium-90 radioembolization for intermediate-advanced hepatocellular carcinoma: a phase 2 study. Hepatology. 2013 May;57(5):1826-37.

66 Salem R, Gordon AC, Mouli S, Hickey R, Kallini J, Gabr A, et al. Y90 Radioembolization Significantly Prolongs Time to Progression Compared With Chemoembolization in Patients With Hepatocellular Carcinoma. Gastroenterology. 2016 Dec;151(6):1155-1163.e2.

67 Zhang Y, Li Y, Ji H, Zhao X, Lu H. Transarterial Y90 radioembolization versus chemoembolization for patients with hepatocellular carcinoma: A meta-analysis. Biosci Trends. 2015 Oct;9(5):289-98.

68 Vilgrain V, Bouattour M, Sibert A, Lebtahi R, Ronot M, Pageaux GP, et al. SARAH: a randomised controlled trial comparing efficacy and safety of selective internal radiation therapy (with yttrium-90 microspheres) and sorafenib in patients with locally advanced hepatocellular carcinoma. J Hepatol. 2017;66(1):S85-6.

69 Chow PK, Gandhi M, Tan SB, Khin MW, Khasbazar A, Ong J, et al.; Asia-Pacific Hepatocellular Carcinoma Trials Group. SIRveNIB: Selective Internal Radiation Therapy Versus Sorafenib in Asia-Pacific Patients With Hepatocellular Carcinoma. J Clin Oncol. 2018 Jul;36(19):1913-21.

70 Bruix J, Raoul JL, Sherman M, Mazzaferro V, Bolondi L, Craxi A, et al. Efficacy and safety of sorafenib in patients with advanced hepatocellular carcinoma: subanalyses of a phase III trial. J Hepatol. 2012 0ct;57(4):821-9.

71 Llovet JM, Ricci S, Mazzaferro V, Hilgard P, Gane E, Blanc JF, et al.; SHARP Investigators Study Group. Sorafenib in advanced hepatocellular carcinoma. N Engl J Med. 2008 Jul;359(4):378-90.

72 Mahvash A, Murthy R, Odisio BC, Raghav KP, Girard L, Cheung S, et al. Yttrium-90 resin microspheres as an adjunct to sorafenib in patients with unresectable hepatocellular carcinoma. J Hepatocell Carcinoma. 2016 Feb;3:1-7.

73 Park JW, Koh YH, Kim HB, Kim HY, An S, Choi JI, et al. Phase II study of concurrent transarterial chemoembolization and sorafenib in patients with unresectable hepatocellular carcinoma. J Hepatol. 2012 Jun;56(6): 1336-42.

74 Pawlik TM, Reyes DK, Cosgrove D, Kamel IR, Bhagat N, Geschwind JF. Phase II trial of sorafenib combined with concurrent transarterial chemoembolization with drug-eluting beads for hepatocellular carcinoma. J Clin Oncol. 2011 Oct;29(30):3960-7.

75 Morimoto M, Numata K, Kondou M, Nozaki A, Morita S, Tanaka K. Midterm outcomes in patients with intermediate-sized hepatocellular carcinoma: a randomized controlled trial for determining the efficacy of radiofrequency ablation combined with transcatheter arterial chemoembolization. Cancer. 2010 Dec;116(23): 5452-60.

76 Veltri A, Moretto P, Doriguzzi A, Pagano E, Carrara G, Gandini G. Radiofrequency thermal ablation (RFA) after transarterial chemoembolization (TACE) as a combined therapy for unresectable non-early hepatocellular carcinoma (HCC). Eur Radiol. 2006 Mar;16(3):661-9.

77 Lencioni R, Crocetti L, Petruzzi P, Vignali C, Bozzi E, Della Pina C, et al. Doxorubicin-eluting bead-enhanced radiofrequency ablation of hepatocellular carcinoma: a pilot clinical study. J Hepatol. 2008 Aug;49(2):217-22.

78 Ikeda M, Shimizu S, Sato T, Morimoto M, Kojima Y, Inaba Y, et al. Sorafenib plus hepatic arterial infusion chemotherapy with cisplatin versus sorafenib for advanced hepatocellular carcinoma: randomized phase II trial. Ann Oncol. 2016 Nov;27(11):2090-6. 
79 Kudo M, Ueshima K, Yokosuka O, Ogasawara S, Obi S, Izumi N, et al.; SILIUS study group. Sorafenib plus low-dose cisplatin and fluorouracil hepatic arterial infusion chemotherapy versus sorafenib alone in patients with advanced hepatocellular carcinoma (SILIUS): a randomised, open label, phase 3 trial. Lancet Gastroenterol Hepatol. 2018 Jun;3(6):424-32.

80 Siegel RL, Miller KD, Jemal A. Cancer statistics, 2016. CA Cancer J Clin. 2016 Jan-Feb;66(1):7-30.

81 Fuchs K, Duran R, Denys A, Bize PE, Borchard G, Jordan O. Drug-eluting embolic microspheres for local drug delivery - State of the art. J Control Release. 2017 Sep;262:127-38.

82 Lahti S, Ludwig JM, Xing M, Sun L, Zeng D, Kim HS. In vitro biologic efficacy of sunitinib drug-eluting beads on human colorectal and hepatocellular carcinoma-A pilot study. PLoS One. 2017 Apr;12(4):e0174539.

83 Fuchs K, Bize PE, Dormond O, Denys A, Doelker E, Borchard G, et al. Drug-eluting beads loaded with antiangiogenic agents for chemoembolization: in vitro sunitinib loading and release and in vivo pharmacokinetics in an animal model. J Vasc Interv Radiol. 2014 Mar;25(3):379-87, 387.e1-2.

84 Bize P, Duran R, Fuchs K, Dormond O, Namur J, Decosterd LA, et al. Antitumoral Effect of Sunitinib-eluting Beads in the Rabbit VX2 Tumor Model. Radiology. 2016 Aug;280(2):425-35.

85 Hagan A, Phillips GJ, Macfarlane WM, Lloyd AW, Czuczman P, Lewis AL. Preparation and characterisation of vandetanib-eluting radiopaque beads for locoregional treatment of hepatic malignancies. Eur J Pharm Sci. 2017 Apr;101:22-30.

86 Denys A, Czuczman P, Grey D, Bascal Z, Whomsley R, Kilpatrick H, et al. Vandetanib-eluting Radiopaque Beads: In vivo Pharmacokinetics, Safety and Toxicity Evaluation following Swine Liver Embolization. Theranostics. 2017 Jun;7(8):2164-76.

87 Sakr OS, Berndt S, Carpentier G, Cuendet M, Jordan O, Borchard G. Arming embolic beads with anti-VEGF antibodies and controlling their release using LbL technology. J Control Release. 2016 Feb;224:199-207.

88 Ludwig JM, Gai Y, Sun L, Xiang G, Zeng D, Kim HS. SW43-DOX \pm loading onto drug-eluting bead, a potential new targeted drug delivery platform for systemic and locoregional cancer treatment - An in vitro evaluation. Mol Oncol. 2016 Aug;10(7):1133-45.

89 Mach RH, Zeng C, Hawkins WG. The $\sigma 2$ receptor: a novel protein for the imaging and treatment of cancer. J Med Chem. 2013 Sep;56(18):7137-60.

90 van Waarde A, Rybczynska AA, Ramakrishnan NK, Ishiwata K, Elsinga PH, Dierckx RA. Potential applications for sigma receptor ligands in cancer diagnosis and therapy. Biochim Biophys Acta. 2015 Oct;1848(10 $10 \mathrm{Pt}$ B):2703-14.

91 Ludwig JM, Xing M, Gai Y, Sun L, Zeng D, Kim HS. Targeted Yttrium 89-Doxorubicin Drug-Eluting Bead-A Safety and Feasibility Pilot Study in a Rabbit Liver Cancer Model. Mol Pharm. 2017 Aug;14(8):2824-30.

92 Yoo SY, Badrinath N, Woo HY, Heo J. Oncolytic Virus-Based Immunotherapies for Hepatocellular Carcinoma. Mediators Inflamm. 2017;2017:5198798.

93 Heo J, Reid T, Ruo L, Breitbach CJ, Rose S, Bloomston M, et al. Randomized dose-finding clinical trial of oncolytic immunotherapeutic vaccinia JX-594 in liver cancer. Nat Med. 2013 Mar;19(3):329-36.

94 Park BH, Hwang T, Liu TC, Sze DY, Kim JS, Kwon HC, et al. Use of a targeted oncolytic poxvirus, JX-594, in patients with refractory primary or metastatic liver cancer: a phase I trial. Lancet Oncol. 2008 Jun; 9(6):53342.

95 Heo J, Breitbach CJ, Moon A, Kim CW, Patt R, Kim MK, et al. Sequential therapy with JX-594, a targeted oncolytic poxvirus, followed by sorafenib in hepatocellular carcinoma: preclinical and clinical demonstration of combination efficacy. Mol Ther. 2011 Jun;19(6):1170-9.

96 Obeid JM, Kunk PR, Zaydfudim VM, Bullock TN, Slingluff CL Jr, Rahma OE. Immunotherapy for hepatocellular carcinoma patients: is it ready for prime time? Cancer Immunol Immunother. 2018 Feb;67(2):161-174.

97 Inarrairaegui M, Melero I, Sangro B. Immunotherapy of Hepatocellular Carcinoma: Facts and Hopes. Clin Cancer Res. 2018 Apr 1;24(7):1518-1524.

98 Sangro B, Gomez-Martin C, de la Mata M, Iñarrairaegui M, Garralda E, Barrera P, et al. A clinical trial of CTLA-4 blockade with tremelimumab in patients with hepatocellular carcinoma and chronic hepatitis C. J Hepatol. 2013 Jul;59(1):81-8.

99 Duffy AG, Ulahannan SV, Makorova-Rusher O, Rahma 0, Wedemeyer H, Pratt D, et al. Tremelimumab in combination with ablation in patients with advanced hepatocellular carcinoma. J Hepatol. 2017 Mar;66(3):545-51.

100 Crocenzi TS, El-Khoueiry AB, Yau TC, et al. Nivolumab (nivo) in sorafenib (sor)-naive and -experienced pts with advanced hepatocellular carcinoma (HCC): CheckMate 040 study. J Clin Oncol. 2017;35(15 suppl):4013.

101 Kudo M. Immuno-Oncology in Hepatocellular Carcinoma: 2017 Update. Oncology. 2017;93 Suppl 1:147-59.

102 Feng D, Hui X, Shi-Chun L, Yan-Hua B, Li C, Xiao-Hui L, et al. Initial experience of anti-PD1 therapy with nivolumab in advanced hepatocellular carcinoma. Oncotarget. 2017 Aug;8(57):96649-55.

103 El-Khoueiry AB, Sangro B, Yau T, Crocenzi TS, Kudo M, Hsu C, et al. Nivolumab in patients with advanced hepatocellular carcinoma (CheckMate 040): an open-label, non-comparative, phase 1/2 dose escalation and expansion trial. Lancet. 2017 Jun;389(10088):2492-502.

104 Slovak R, Ludwig JM, Gettinger SN, Herbst RS, Kim HS. Immuno-thermal ablations - boosting the anticancer immune response. J Immunother Cancer. 2017 Oct;5(1):78.

105 Ghodadra A, Bhatt S, Camacho JC, Kim HS. Abscopal Effects and Yttrium-90 Radioembolization. Cardiovasc Intervent Radiol. 2016 Jul;39(7):1076-80. 